Bioscientia Medicina: Journal of Biomedicine \& Translational Research

Journal Homepage: www.bioscmed.com

\title{
Ductus Omphalocele Mesenteric Persisten: A Case Reports
}

\section{Siwi Bagus Ajiningrat ${ }^{*}$, Nunik Agustriani2}

1 Specialized Residency Training, Department of Surgery, Faculty of Medicine, Universitas Negeri Sebelas Maret / Dr. Moewardi, Solo, Indonesia

2 Division Pediatric Surgery, Department of Surgery, Faculty of Medicine, Universitas Negeri Sebelas Maret / Dr. Moewardi, Solo, Indonesia

\section{A R T I C L E I N F O}

\section{Keywords:}

Ductus omphalomecenterica

Surgery

Case reports

*Corresponding author:

Siwi Bagus Ajiningrat

\section{E-mail address:}

\section{bagusajiningrat@gmail.com}

All authors have reviewed and approved the final version of the manuscript.

https://doi.org/10.37275/bsm.v6i2.446

\begin{abstract}
A B S T R A C T
Background: The ductus omphalomecenterica is a normal embryological structure where it serves to connect the midgut of the fetus to the yolk sac. Usually, this ductus will disappear at 9 weeks gestation. However, if this condition does not occur, then it can cause various anomalies to appear in the fetus. Case Presentation: The patient was reported to be hospitalized with the chief complaint of choking. Echocardiography examination with the results of the examination found the presence of cyanotic congenital heart disease (CHD). The patient was referred to pediatric surgery with a diagnosis of persistent mesenteric duct omphalocele. Terminal ileum anastomoses resection laparotomy was performed. Conclusion: After surgery due to complications of pneumonia and sepsis, the patient died.
\end{abstract}

\section{Introduction}

The ductus omphalomecenterica is a normal embryological structure where it serves to connect the midgut of the fetus to the yolk sac. Usually, this ductus will disappear at 9 weeks gestation. However, if this condition does not occur, then it can cause various anomalies to appear in the fetus. ${ }^{1}$ Persistent ductus omphalomecentericaus is rare. In 1812, Meckel described the involution of the ductus omphalomecenterica resulting in a persistent diverticulum. Since then Cullen has reviewed the literature on the irregularity of the involution of the preumbilical structures. He reported forty-six cases of patent ductus omphalomecentericaa. Most were observed at birth, although two cases were recognized when the patients were 16 and 28 years old. Surgery to correct the condition was performed in nineteen cases, resulting in fourteen recoveries and five deaths. Since then, many similar or related anomalies of the umbilical cord have been noted. Garratt 3 reported the persistence of the vitelline channel in twins. Other reports of persistent omphalomesenteric ductus have been made by O'Neil, Barron, Parker, Guthrie, Dietsen and others. In all, eighteen examples of this type have been published.2-8

The persistent vitelline ductus is the most common congenital anomaly of the small intestine. Meckel's 
diverticulum, a remnant of the elongated vitelline ductus, is the most common cause, occurring in $2 \%$ to $4 \%$ of the population. The persistent presence of the vitelline ductus can then lead to omphalomecenterica cysts. If all these structures are present for a long time, a persistent ductus omphalomecenterica is formed as in this case. ${ }^{9}$

\section{Case Presentation}

The patient was reported to be hospitalized on December 25, 2019, with the chief complaint of choking. The patient choked 40 minutes before admission to the hospital while drinking breast milk by breastfeeding directly from the mother. The patient coughs and looks bluish on the face for 5 minutes, looks breathless than the baby cries. Fever and history of cough and cold were denied. The patient appears to be crying loudly with active movements. No fever and cold cough. The patient was then admitted to the neonatal HCU for infection. On December 26, 2019, the patient underwent an echocardiography examination with the results of the examination finding cyanotic congenital heart disease (CHD). On December 30, 2019, the patient was consulted to the pediatric surgery department with a persistent diagnosis of omphalocele mesenteric ductus (figure 1). On January 2, 2020, the patient underwent surgical excision of the ductus (figure 2), the results were excision with a size of $2 \times 2 \mathrm{sm}$ (figure 3 ). The operation was successful and the patient was then admitted to the NICU. While in treatment, complications were found in the patient based on the results of the babygram photo examination on January 13, 2020, pneumonia was found. On January 18, 2020, the baby was found to have neonatal sepsis and the baby died on January 20, 2020, with postoperative laparotomy ec ileal necrosis with pneumonia, neonatal sepsis, and cyanotic Congenital Heart Disease Ventricular Septal Defect (VSD). The history of delivery revealed that the baby was born to a mother G3P1A1 at the age of 28 years. The baby was born at 36 weeks of gestation due to premature rupture of the membranes 7 hours before the baby was born. The baby was born spontaneously, immediately cried, with a birth weight of 2050 gr. Colored and smelly amniotic fluid. The baby was then treated in the nursery for 5 days and an orogastric tube (OGT) was attached.

Physical examination revealed a respiration rate of 32 times per minute and a heart rate of 164 times/minute. Meanwhile, normal body temperature and examination of the head, chest and extremities showed no abnormalities. On an abdominal examination found the abdominal wall parallel to the chest wall, there is a picture of organs outside the abdominal cavity and odorless. Investigations in the form of routine blood showed normal results. Radiological examination revealed pneumonia. This patient was diagnosed with neonatal infection et causa persistent omphalocele mesenteric ductus with mild respiratory distress et causa pneumonia and sepsis neonatorum et causa congenital heart disease cyanotic ventricular septal defect.

Laparotomy operation was performed for Terminal Ileum Anastomose Resection on January 20, 2020, with the procedure the patient was supine on the operating table under general anesthesia, then closed with a sterile perforated drape. Then, the colon prolapse was identified, which was blue-black and there was tissue necrosis. Next, a midline supraumbilical transverse incision was made, identification of ileal distention, colon exited through the defect, and necrosis was found. Transverse ileal resection \& ileal anastomoses were performed. Then close the defect using a 3.0 absorbable multifilament thread, decompress intra-abdominal organs and evaluate bleeding. Then sew the perineum, fascia, attach the drain followed by sewing the subcutis and cutis. 


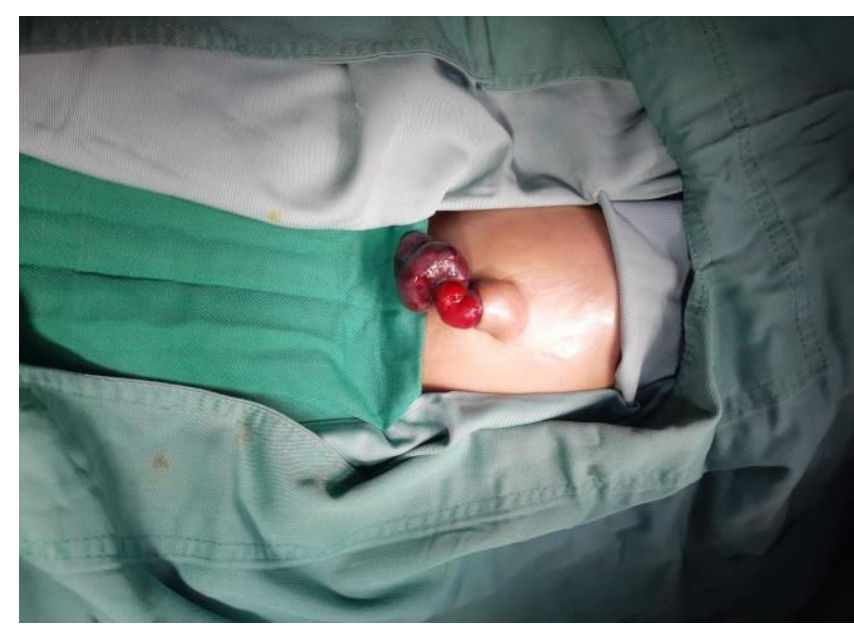

Figure 1. omphalocele in a patient without an occlusion
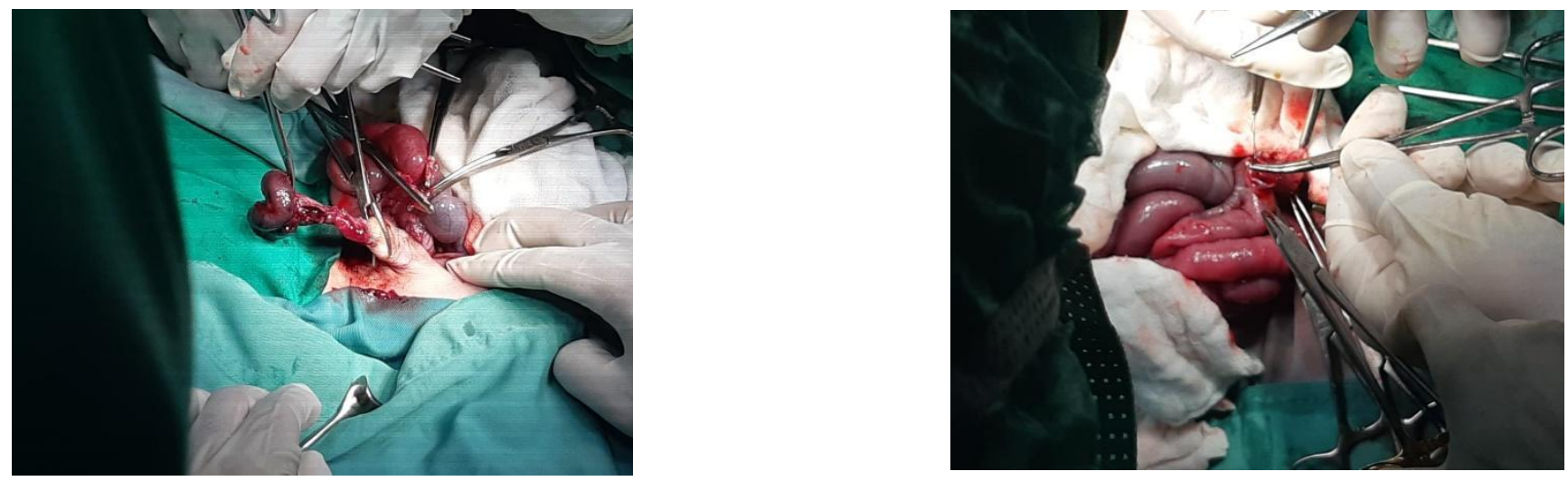

Figure 2. Surgical treatment on an omphalocele

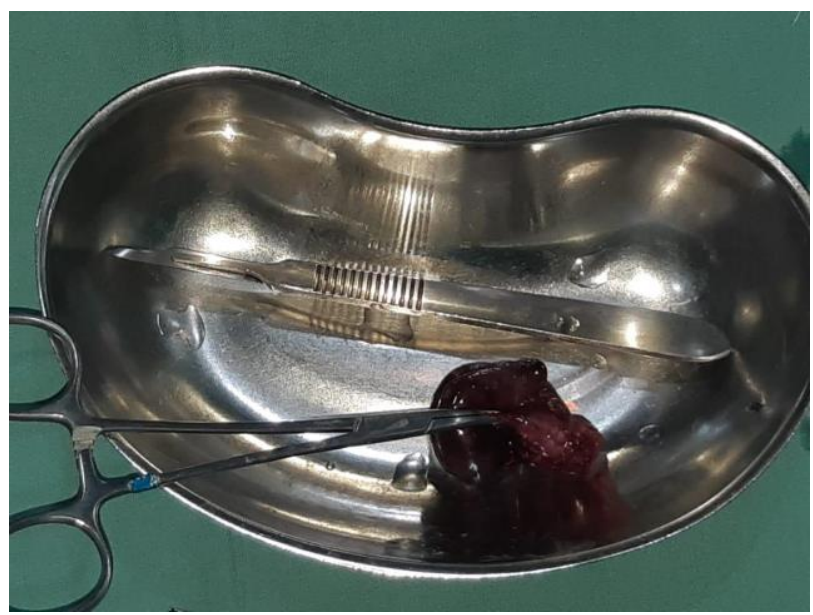

Figure 3. Results of surgery on a patient

After monitoring the patient's condition postoperatively, the patient appeared blue, breath was not spontaneous, heart rate was not palpable and the patient was in a coma. Then cardiopulmonary resuscitation was performed, but the patient's life could not be saved and the patient died. 


\section{Discussion}

Omphalomesenteric tract cysts are rarely reported. A study found only three cases of omphalomesenteric cysts in 217 children with remnants found attached to the umbilicus, intestine, or both. Males had a higher incidence than females $(4: 1)$ as with other omphalomesenteric anomalies and were not associated with maternal age, gravidity, race, or prematurity. has a variety of presentations. In the newborn, omphalomesenteric remnants may be present in the omphalocele. Another study reported a case similar to ours in a newborn but had a cyst containing clear fluid instead of meconium. 10,11

In this case, a large cyst was seen in the omphalocele sac, outside the peritoneal cavity. It is a localized dilatation in the area of the Meckel diverticulum and communication at both ends with the small intestine and contains meconium. The possibility of a cystic duplication variant of the small intestine was ruled out as it lies on the antimesenteric side of the intestine with no aberrant vascular supply and shares a common wall. Thus the impression of a residual omphalomesenteric variant and possibly an omphalomesenteric cyst is made. ${ }^{12,13}$

Omphalomesenteric cysts are variable in diameter and appear as cystically dilated segments of the small intestine. They are usually lined by columnar epithelium that resembles the small intestine, large intestine, or stomach. Ectopic pancreatic tissue may be present. The gross and histological characteristics of the specimen in our case are similar to those reported in the literature supporting the possibility of an omphaloenterenteric cyst. However, no ectopic tissue was identified in our case. ${ }^{14-16}$

\section{Conclusion}

Omphalocele is a condition caused by a defect in the abdominal wall. In addition to physical examination, investigations are also needed in establishing the diagnosis of the persistent omphalomesenteric duct. One of the supporting examinations here is a radiological examination with Ultrasonography. The first treatment is to repair the main wall damage with complete reduction.

\section{References}

1. Azmy A, Boddy SA, Eckstein HB. Torsion of gall bladder, embedded in an accessory lobe of liver in a neonate with Beckwith syndrome. $\mathrm{Z}$ Kinderchir Grenzgeb 1980; 30: 277-279.

2. Chattopadhyay A, Prakash B, Nagendhar Y, Kumar V. Patent omphalomesenteric ductus and exomphalos minor: a rare and interesting association. Int Surg. 2007; 92: 254-6.

3. Cohen MM Jr. Beckwith-Wiedemann syndrome: historical, clinicopathological, and etiopathogenetic perspectives. Pediatr Dev Pathol 2005; 8: 287-304.

4. Coran, AG, Caldamone, A., Adzick, NS, Krummel, TM, Laberge, JM and Shamberger, R., Pediatric surgery E-book. 2012; 2. Elsevier Health Sciences.

5. Elliott M, Bayly R, Cole $\mathrm{T}$, et al. Clinical features and natural history of BeckwithWiedemann syndrome: presentation of 74 new cases. Clin Genet 1994; 46:168-174.

6. Festen C, Severijnen RS, Van Der Staak FH. Gallbladder embedded in an accessory liver lobe in umbilical cord hernia. J Pediatr Surg 1988; 23: 978-979.

7. Gaisie G., Curnes JT, Scatliff JH, et al.: Neonatal intestinal obstruction from omphalomesenteric ductus remnants. AJR Am J Roentgenol, 1985; 144: 109-112.

8. Khati NJ, Enquist EG, Javitt MC. Imaging of the umbilicus and periumbilical region. Radiographics 1998; 18: 413-431.

9. Kleiner O., Cohen Z., Finaly R., Mordehai J., Mares AJ: Unusual presentation of omphalomesenteric ductus remnant: a variant of mesodiverticular band causing intestinal obstruction. J Peduatr Surg, 2000; 35: 11361137.

10. Nicol JW, MacKinlay GA. Meckel's diverticulum in exomphalos minor. JR Coll Surg Edinb. 1994; 39: 6-7.

11. O'Neill, JA, Grosfeld, JL, Fonkalsrud, EW and Coran, AG, 2003. Principles of pediatric surgery. Mosby Inc. 
12. Pereira RM, Simoes e Silva AC, Leite VH, et al. Successful management of concomitant omphalocele, accessory hepatic lobe, and biliary atresia in a 44-day-old boy. $\mathrm{J}$ Pediatr Surg 2005; 40: e21- e24.

13. Rasool N, Hussain I, Akhtar J, Ahmed S, Aziz A. Various presentations of omphalomesenteric ductus remnants in children. J Coll Physicians Surg Sir. 2002; 12: 204-7.

14. Ratan SK, Rattan KN, Kalra R, Maheshwari J, Parihar D, Ratan J. omphalomesenteric duct cyst as a content of omphalocele. Indian $\mathrm{J}$ Pediatrics. 2007; 74: 500-02.

15. Steigman CK, Uri AK, Chatten J, et al. Beckwith-Wiedemann syndrome with unusual hepatic and pancreatic features: a case expanding the phenotype. Pediatr Pathol 1990; 10: 593-600.

16. Takano H, Sato Y, Kao SC, et al. Enlarging giant liver cyst in Beckwith-Wiedemann syndrome. Pediatr Radiol 1997; 27: 619-620. 